\title{
SOME NOTES ON THE HYBRID BETWEEN CAMPANULA ISOPHYLLA MOR. AND C. PYRAMIDALIS L.
}

\author{
A. MUSCH and T. W. J. GADELLA \\ Instituut voor Systematische Plantkunde, Utrecht
}

\section{SUMMARY}

The hybrid $(2 n=33)$ between Campanula isophylla $(2 n=32)$ and C. pyramidalis $(2 n=34)$ is described. Some notes are given on the relationship between both species.

\section{INTRODUCTION}

Hybrids between species of the genus Campanula are rare, not only in nature but also in gardens. This indicates that strong interspecific reproductive barriers are present in this genus, most species of which are strictly or predominantly allogamous.

Gadella (1964, 1967) published the results of hybridization experiments between some species of the genus. Many interspecific crosses were unsuccesful, whereas in other cases some F-1 plants could be obtained, which did not come into flower. Only in a very few instances the hybrids produced some flowers, e.g. the hybrid $(2 \mathrm{n}=32)$ between Campanula trachelium $(2 \mathrm{n}=34)$ and C. glomerata $(2 \mathrm{n}=30)$, but usually they turned out to be completely sterile.

The junior author (G.) obtained 14 seeds by crossing the allopatric species C. pyramidalis (O) and C. isophylla ( $\left.\sigma^{\star}\right)$. These seeds germinated and produced some small and weak seedlings with yellowish-green leaves. None of these hybrids reached the flowering state and all seedlings died within a few weeks. The senior author (M.) repeated this interspecific cross and obtained some F-1 plants that produced many flowers. In this paper the results of the latter crossing experiment are dealt with.

\section{MATERIAL AND METHODS}

The flowers of $C$. isophylla were emasculated. Access of insects was prevented by bags enveloping the flowers. When the stigmata of the emasculated flowers spread, the pollen of $C$. pyramidalis (from a just opening flower) was placed on the stigma of $C$. isophylla.

Roottips of the hybrid were used for cytological studies.

\section{RESULTS}

30 Seeds were obtained, 3 of which were able to germinate. One of the hybrids died, the remaining two reached the flowering state in 1971 . In 1972 only one 
hybrid was still alive and produced many flowers (fig. 1). Back-crosses of the hybrid to both parents were unsuccessful. The differences between the parents and the hybrid are described in the table. The chromosome number of the hybrid turned out to be $2 n=33$.

Table

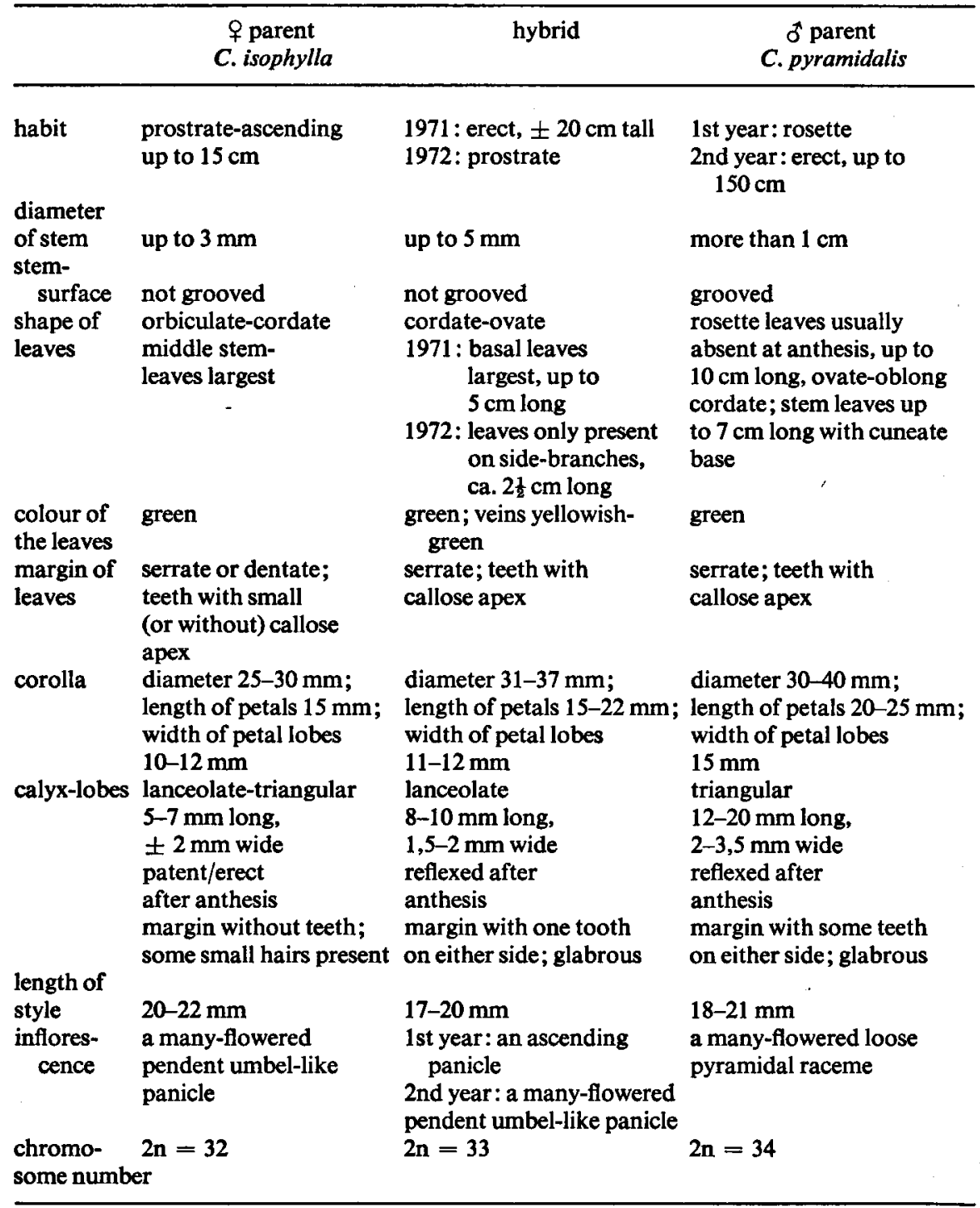




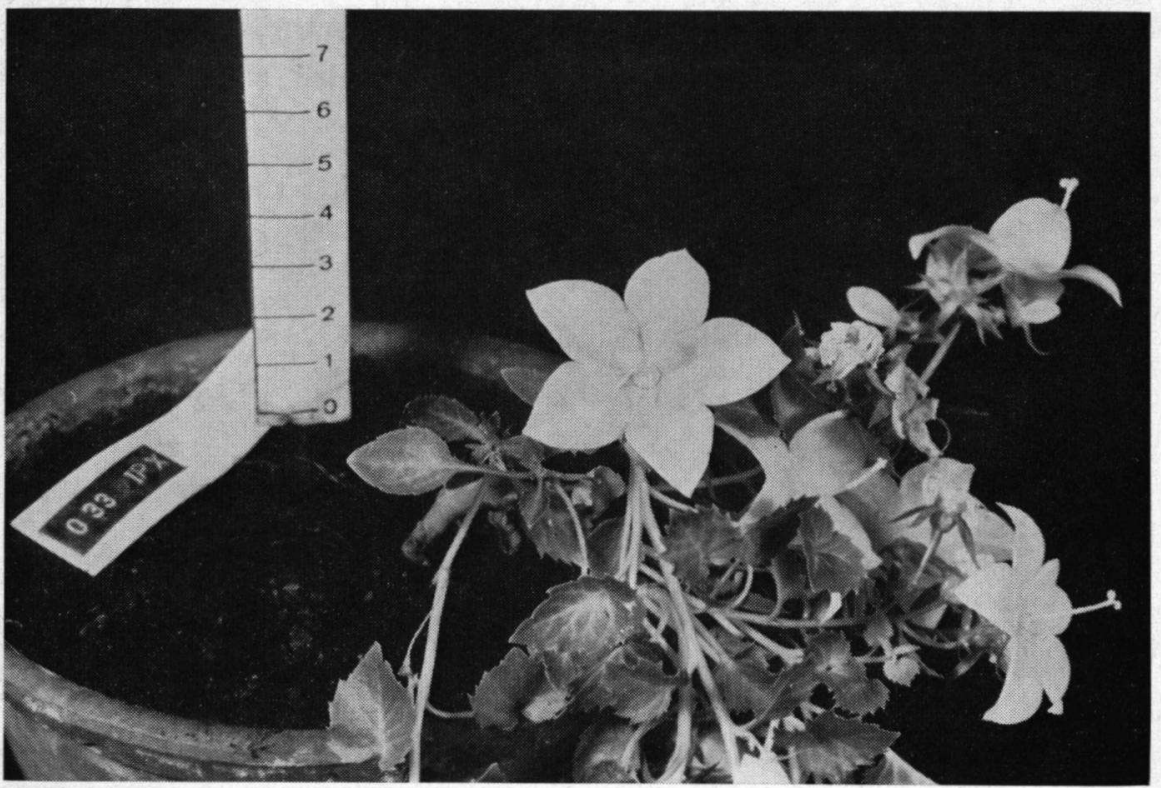

Fig. 1. The hybrid $(2 \mathrm{n}=33)$ between C. pyramidalis $(2 \mathrm{n}=34)$ and $C$. isophylla $(2 \mathrm{n}=32)$.

\section{DISCUSSION}

The hybrid did not produce viable seeds. This was to be expected, since most species of the isophyllae-group are not self-compatible (DAMBOLDT 1965). The pollen grains of the hybrid were partially normal, partially very small and empty. The fertility of the hybrid can be tested by crossing this plant with another artificially produced hybrid or by backcrossing to either parent. Backcrossing to the parental species did not result in the formation of viable seeds.

The chromosome number of the hybrid $2 n=33$ is intermediate between that of C. isophylla (2n = 32, MERXMülleR \& DAMBOLDT 1962; GADELLA 1964) and of C. pyramidalis (2n = 34, Podlech \& Damboldt 1962; Gadella 1964).

The hybrid is interesting both from a taxonomic and from an evolutionary point of view. Both parental species have erect capsules, those of $C$. isophylla dehiscing with a basal pore, those of $C$. pyramidalis with a medio-lateral pore. Both species have cordate leaves and small chromosomes (smaller than 2 micron). FIORI (1927) placed both species in the section Elatines. DAMBOLDT(1965), however, is of the opinion that this group is heterogeneous and excludes a number of species (among which $C$. pyramidalis and $C$. versicolor) from the group of isophyllous campanulae. Damboldt was able to demonstrate that in Fiori's section plants with $n=16$ and $n=17$ occur. Hybrids could not be produced between the plants belonging to the $n=16$ and $n=17$ group. The fact, however, that the senior author could obtain a vigorous hybrid by crossing $C$. pyramidalis 
and $C$. isophylla shows that both species are very closely related and that a close connection between the chromosome numbers $2 n=32$ and $2 n=34$ must exist.

Perhaps both species have developed from the same ancestral stock. The number $2 n=32$ of $C$. isophylla does not seem to be derived from $x=8$ as is the case in such species as C. persicifolia $(2 \mathrm{n}=16)$, C. latiloba $(2 \mathrm{n}=16)$, and C. stevenii $(2 \mathrm{n}=32)$. These species share the following characters: lanceolate leaves, erect capsules with latero-apical pores, long chromosomes (4-6 micron). The number $2 n=32$ may be the result of reduction of $2 n=34$, but further research (i.a. a detailed study of the meiosis of the hybrid) is required to prove this hypothesis.

\section{REFERENCES}

DAmBoldt, J. (1965): Zytotaxonomische Revision der isophyllen Campanulae in Europa. Bot. Jb. 84: 302-358.

FIORI, A. (1927): Nuova flora analitica d'Italia II. Florence.

Gadella, TH. W. J. (1964): Cytotaxonomic studies in the genus Campanula.Wentia 11: 1-104.

- (1967): The taxonomic significance of two artificially produced hybrids in the genus Campanula. Acta Bot. Neerl. 15: 624-629.

MerXmüller, H. \& J. DAmBoldt (1962): Die Chromosomenzahlen einiger rupicoler mediterraner Campanulae. Ber. Deutsch. Bot. Ges. 75: 233-236.

Podlech, D. \&. J. DAmBoldt (1964): Zytotaxonomische Beiträge zur Kenntnis der Campanulaceen in Europa. Ber. Deutsch. Bot. Ges. 76: 360-369. 